\title{
Epidemiological and Clinical Pattern of Open Fractures of Long Bones of the Lower Limbs in the South-West Region of Cameroon: A 5-Year Review
}

\author{
Chunteng T. Nana ${ }^{*}{ }^{*}$, Fokam Pius ${ }^{1}$, Mokake N. Martin1, Morane Mbongnu' ${ }^{1}$, Sam D. Movuh', \\ Freddy Mertens Bombah², Ndasi Henry'1, Palle J. Ngunde1, A. Chichom-Mefire1 \\ ${ }^{1}$ Department of Surgery, Faculty of Health Sciences, University of Buea, Buea, Cameroon \\ ${ }^{2}$ Department of Surgery and Specialties, Faculty of Medicine and Pharmaceutical Sciences, University of Douala, Douala, Cameroon \\ Email: *nana2theo@yahoo.fr
}

How to cite this paper: Nana, C.T., Pius, F., Martin, M.N., Mbongnu, M., Movuh, S.D., Bombah, F.M., Henry, N., Ngunde, P.J. and Chichom-Mefire, A. (2021) Epidemiological and Clinical Pattern of Open Fractures of Long Bones of the Lower Limbs in the South-West Region of Cameroon: A 5-Year Review. Open Journal of Orthopedics, 11, 278-287.

https://doi.org/10.4236/ojo.2021.119026

Received: August 9, 2021

Accepted: September 20, 2021

Published: September 23, 2021

Copyright $\odot 2021$ by author(s) and Scientific Research Publishing Inc. This work is licensed under the Creative Commons Attribution International License (CC BY 4.0).

http://creativecommons.org/licenses/by/4.0/ (c) (i) Open Access

\begin{abstract}
Background: An open fracture is an injury in which the fracture site and/or hematoma communicates with the external environment. It is associated with significant morbidity and disability and is a challenge to the surgical team. The lower extremities are the most often exposed to traumatic injuries compared to other anatomical parts of the body. Patterns of open fractures differ with different mechanisms of injury and the segment of the long bone affected. The correct and timely management of open fractures is beneficial to the patients and leads to a more favorable outcome. This study aimed at describing the pattern of open fractures of long bones of the lower limb treated in 3 major hospitals of the south west region, Cameroon. Methodology: This was a hospital-based retrospective review of files of patients with open fractures of long bones of the lower limb managed at the surgical units of three secondary health facilities in the South-West region of Cameroon from the $1^{\text {st }}$ of January 2015 to the $31^{\text {st }}$ of December 2019. The socio-demographic characteristics, clinical presentation, treatment modalities, and outcomes were recorded. The data was stored and analyzed using Epi info version 7.0 and SPSS version 23.0 respectively. Results: A total of 195 files of patients aged 8 to 80 years were studied. The main age group affected was between $20-40$ years. There were $147(75.4 \%)$ males and $48(24.6 \%)$ females giving a sex-ratio of 3.1:1. The most common cause was road traffic crashes 142 (72.8\%). In 98 cases $(50.3 \%)$, the left side was more involved. The tibia was the most common long bone affected in $75(38.5 \%)$ cases. Comminuted fracture was the most common fracture pattern encountered in 126 cases (64.6\%). A total of 76 (39\%) fractures were graded Gustilo-Anderson IIIA. External fixator was
\end{abstract}


used in 112 cases (57.1\%) and internal fixator in 86 cases (42.9\%). We recorded 127 (65.1\%) cases of wound infection and 143 (73.3\%) cases of limb shortening as the most common complications. Other complications include: 20 cases $(17.1 \%)$ of mal-union, 27 cases $(22.5 \%)$ of delayed union, 18 cases (15.1\%) of non-union and 50 cases $(38.5 \%)$ chronic osteomyelitis. We recorded a mortality of $2.1 \%$. Gustilo IIIB and IIIC were associated to chronic osteomyelitis $(\mathrm{P}=0.02)$. Conclusion: Open fractures of long bones of the lower limb affect the active age group of the population and road traffic crashes are the most common causes. It tends to affect the left side and the tibia being the most fractured long bone. A reasonable proportion of these fractures subsequently get infected. Comminuted fracture is the common fracture pattern.

\section{Keywords}

Open Fractures, Long Bones, Lower Limb

\section{Introduction}

An open fracture is defined as an injury in which the fracture site and/or fracture hematoma communicates with the external environment [1] [2]. Open fractures of long bones of the lower limb are often due to high energy injuries and are often associated with other life-threatening conditions secondary to poly-trauma. They equally pose other serious risks such as neurovascular injuries, soft tissue lesions, wound contamination and skin degloving which make them more likely to have long term complications like chronic bone infections, delayed unions, non-unions amputation [3] [4].

The Gustilo-Anderson (GA) classification which is based on the energy level, size of the wound, degree of soft tissue destruction, contamination, and neurovascular state is the most commonly used system to classify and determine the severity of open fractures [5] [6].

Management of lower limb open fractures still remains one of the major challenges in orthopedic practice. Early administration of appropriate antibiotics, thorough surgical debridement, proper skeletal stabilization and early soft tissue coverage have been considered as the main steps to optimize outcome [7].

In low-middle income sub Saharan African communities, the burden of open fractures is on the rise, and most patients seek surgical care after a certain delay presenting with severe injuries or sequellae that are difficult to treat with the diagnostic and therapeutic means available in the local facilities [8] [9].

The shortage of appropriate hospital facility, limited human resource and financial constraints complicate the treatment of the open fractures of extremities in our context. In order to provide data on the subject, we aimed to describe the epidemiological and clinical aspects of open fractures of long bones of the lower limbs treated in the southwest region of Cameroon. 


\section{Materials and Methods}

\subsection{Study Design}

This was a 5 year ( $1^{\text {st }}$ of January 2015 to $31^{\text {st }}$ of December 2019) hospital based retrospective analysis of files of patients with open fractures of long bones of the lower limbs, managed at the Baptist Hospital Mutengene, Buea and Limbe Regional Hospitals. These are the main hospitals performing orthopedic surgeries in the South West region of Cameroon.

We included all files of patients with open fractures of long bones of the lower limb that were admitted and treated in these hospitals within the study period. Files of patients with incomplete data were excluded in the study.

Ethical clearance was obtained from the Institutional Review Board (IRB) of the Faculty of Health Sciences, University of Buea. Administrative approvals were obtained from the Faculty of Health Sciences, Regional delegation of Public health in the South West region, Baptist Hospital Mutengene, Buea and Limbe Regional Hospitals.

\subsection{Data Collection}

Files of patients who had open fractures of long bones of the lower limb who were admitted and treated were assessed. Data concerning the socio-demographics, mechanism of injury, fracture pattern, type of open fracture, management modalities outcomes, and follow-up were obtained from the files of patients. Uniformity in data collected was insured by pre-structured data collection forms.

\subsection{Data Analysis and Management}

Data was entered into to Microsoft Excel and analyzed using SPSS version 23. Findings were presented using frequency distribution tables and charts with all statistics presented at a $95 \%$ level of confidence interval with $\mathrm{p}<0.05$ considered statistically significant.

\section{Results}

A total of 195 files of patients with 195 fractures of long bones of the lower limb were enrolled in the study. There were 98 patients who had fractures affecting the left lower limb, 96 affecting the right lower limb, and one affecting both lower limbs.

\subsection{Socio-Demographic Characteristics}

The ages of the patients ranged from 8 to 80 years with a mean age of $34.11 \pm$ 13.67. The age range of $20-40$ years was most represented $(125,64.1 \%)$. There were 147 males $(75.4 \%)$ and 48 females (24.6\%) giving a sex-ratio of 3.1:1 (see Table 1).

The majority 174 (89.2\%) had both primary and secondary education. Only 14 (7.2\%) had completed higher education while 7 (3.6\%) had no formal education. 
Table 1. Socio-demographic characteristics.

\begin{tabular}{|c|c|c|c|}
\hline Variable & Levels & Frequency & Percentage \\
\hline \multirow{6}{*}{ Age group } & Mean \pm SD & $34.11 \pm 13.67$ & \\
\hline & $<20$ years & 20 & 10.3 \\
\hline & $20-40$ Years & 125 & 64.1 \\
\hline & $40-60$ years & 37 & 19.0 \\
\hline & $>60$ years & 13 & 6.7 \\
\hline & Total & 195 & 100.0 \\
\hline \multirow{3}{*}{ Sex } & Female & 48 & 24.6 \\
\hline & Male & 147 & 75.4 \\
\hline & Total & 195 & 100.0 \\
\hline \multirow{5}{*}{ Education } & Not attended & 7 & 3.6 \\
\hline & Primary & 85 & 43.6 \\
\hline & Secondary & 89 & 45.6 \\
\hline & University & 14 & 7.2 \\
\hline & Total & 195 & 100.0 \\
\hline \multirow{4}{*}{ Occupation } & Formal & 29 & 14.9 \\
\hline & Informal & 139 & 71.3 \\
\hline & Student & 27 & 13.8 \\
\hline & Total & 195 & 100.0 \\
\hline \multirow{5}{*}{ Marital status } & Divorced & 1 & 0.5 \\
\hline & Married & 85 & 43.6 \\
\hline & Single & 105 & 53.8 \\
\hline & Widow (er) & 4 & 2.1 \\
\hline & Total & 195 & 100.0 \\
\hline
\end{tabular}

The majority of the participants 139 (71.3\%) had informal occupation (farmer, business, bike-rider, builder, carpenter, hairdresser, driver, maid, and others) and only $29(14.9 \%)$ had a formal occupation (civil servants, technicians, and engineers) while the rest were students 27 (13.8\%).

\subsection{Injury Characteristics and Clinical Presentations (see Table 2)}

A majority of cases were due to road traffic injuries 142 (72.8\%) followed by gunshots $40(20.5 \%)$. As many as $88(62 \%)$ of the cases due to road traffic accidents involved drivers and pillion riders.

Concomitant fracture of the tibia and fibula was observed in $76(39.0 \%)$ cases. The tibia 75 (38.5\%) was the most isolated lower limb long bone affected, followed by the femur $32(16.4 \%)$ and only $3(1.5 \%)$ cases of the fibula. Majority of the fracture type were Gustilo-Anderson II and III. Grade IIIA was the most common with $76(39.0 \%)$ cases, followed by grade IIIB with 56 (28.7\%) and grade II with 46 (23.6\%). Grade IIIC fractures were in minority with 17 (8.7\%) 
Table 2. Clinical characteristics of open fractures.

\begin{tabular}{|c|c|c|c|}
\hline Characteristics & Levels & Frequency & Percentage \\
\hline \multirow{6}{*}{ Bone involved } & Femur & 32 & 16.4 \\
\hline & Femur and tibia & 9 & 4.6 \\
\hline & Fibula & 3 & 1.5 \\
\hline & Tibia & 75 & 38.5 \\
\hline & Tibia and fibula & 76 & 39.0 \\
\hline & Total & 195 & 100.0 \\
\hline \multirow{5}{*}{ Gustilo Anderson class } & Type II & 46 & 23.6 \\
\hline & Type IIIA & 76 & 39.0 \\
\hline & Type IIIB & 56 & 28.7 \\
\hline & Type IIIC & 17 & 8.7 \\
\hline & Total & 195 & 100.0 \\
\hline \multirow{7}{*}{ Fracture pattern } & Comminuted & 126 & 64.6 \\
\hline & Oblique & 26 & 13.3 \\
\hline & Segmental & 9 & 4.6 \\
\hline & Spiral & 4 & 2.1 \\
\hline & Transverse & 28 & 14.4 \\
\hline & Wedge & 2 & 1.0 \\
\hline & Total & 195 & 100.0 \\
\hline \multirow{4}{*}{ Side } & Both & 1 & 0.5 \\
\hline & Left & 98 & 50.3 \\
\hline & Right & 96 & 49.2 \\
\hline & Total & 195 & 100.0 \\
\hline \multirow{4}{*}{ Segment involved } & Distal & 80 & 41.0 \\
\hline & Middle & 75 & 38.5 \\
\hline & Proximal & 40 & 20.5 \\
\hline & Total & 195 & 100.0 \\
\hline \multirow{7}{*}{ Mechanism of injury } & Assault & 4 & 2.1 \\
\hline & Crush (other than RTI) & 4 & 2.1 \\
\hline & Fall & 4 & 2.1 \\
\hline & Gunshot & 40 & 20.5 \\
\hline & RTI & 142 & 72.8 \\
\hline & Sport injury & 1 & 0.5 \\
\hline & Total & 195 & 100.0 \\
\hline
\end{tabular}

RTI: Road traffic injuries.

cases.

The most common fracture pattern observed were: comminuted fracture pattern $126(64.6 \%)$, followed by transverse fracture pattern $28(14.4 \%)$ and oblique fracture $26(13.3 \%)$. These fracture patterns were observed to affect mostly the left side of the lower limb 98 (50.3\%) compared to the right 96 (49.2\%). The dis- 
tal bone segment was more common at $80(41.0 \%)$ cases, followed by the middle segment at $75(38.5)$ cases and $40(20.5 \%)$ cases for the proximal bone segment.The majority of the patients,104, (53.5\%) presented to the hospital after 6 hours and $91(46.7 \%)$ cases presented to the hospital within 6 hours. The time from injury to surgery was beyond 6 hours in 55\% of fractures and about $45 \%$ of fractures were operated within 6 hours. The average time between injury and surgery was 29.3 hours.

\subsection{Treatment Modalities and Complications (see Table 3)}

External fixator was used as initial method of fixation in 112 cases $(57.1 \%)$ and internal fixator in 83 cases $(42.9 \%)$. The complication with several unplanned procedures was wound infection 127 (65.1\%) which was managed by interval debridement, wound irrigation, antibiotic beads (mostly Gentamycin), vacuum-assisted closure (VAC). Flaps were used to cover extensive loss of soft tissue. $t$ we recorded four cases of death: two from grade IIIC fractures and the rest from causes unrelated to their fractures. Unfortunately, there four cases of death; two from grade IIIC fractures and the others from causes unrelated to their fractures.

\section{Discussion}

An estimated $77 \%$ of preventable deaths associated with inadequate surgical care are attributable to injuries, and $90 \%$ of injury-related deaths worldwide occur in low- and middle-income countries like ours where the use of formal medical services after injury usually require potentially crippling out-of-pocket expenditures [10] [11]. Open fractures of the lower extremity are the most common open long bone injuries, with an annual incidence of 3.4 per 100,000 [12] [13].

In urban Cameroon, open fractures of long bones of the lower limb accounted for $23.9 \%$ of road traffic injured victims [14]. In south west Cameroon, open

Table 3. Listing of complications.

\begin{tabular}{cccc}
\hline Variables & \multicolumn{2}{c}{ Type of fixation } & p-value \\
\cline { 2 - 3 } Wound Infection & External & Internal & 0.001 \\
Amputation & $84(43.1)$ & $43(22.1)$ & 0.015 \\
Limb shortening & $14(7.2)$ & $2(1.0)$ & 0.002 \\
Salvaged Limb & $93(47.7)$ & $50(25.6)$ & 0.115 \\
Flap reconstruction & $94(48.2)$ & $76(39.0)$ & 0.040 \\
Chronic osteomyelitis & $11(5.6)$ & $2(1.0)$ & 0.0005 \\
Fracture re-displacement & $40(30.8)$ & $10(7.7)$ & 0.030 \\
Mal-union & $22(11.3)$ & $7(3.6)$ & 0.016 \\
Delayed union & $16(13.7)$ & $4(3.4)$ & 0.084 \\
Non-union & $19(15.8)$ & $8(6.7)$ & 0.032
\end{tabular}


fractures accounted for $60.29 \%$ of injured [15].

Efforts to expand access to trauma care have been limited by the lack of injury epidemiology data and a poor understanding of barriers to use of care [16]. This study was aimed at describing the epidemiological and clinical patterns of open fractures of long bones of the lower limbs managed at the Baptist Hospital Mutengene, Buea, and Limbe Regional Hospitals which are the main hospitals managing orthopedic trauma in the South west region of Cameroon. This retrospective review included 195 cases within the 5 years period.

\subsection{Socio Demography}

This study shows that the most vulnerable age group for open fractures of long bones of the lower limbs in the South west region of Cameroon is the young population within the age group of 20 - 40 years. This is comparable to findings in other studies [12] [15]. This range is the active and productive age, and the greatest human resources of any nation. The involvement of more males than females in this study correlates with findings by other authors [15] [17] [18]. Males are by their nature more active and likely to be involved in riskier activities than females. About 50\% $(n=89)$ had at least secondary education.

\subsection{Cause of Injury}

Road traffic crash accounted for $72.8 \%(\mathrm{n}=142)$ of cases. This is similar to studies carried out in other sub-Saharan African countries [17] [19] [20]. The majority of those involved in road traffic crashes were drivers (bike-riders and taxi drivers). This is because these are the most common commercial means of transportation in the south west region of Cameroon. Most of these drivers had no formal higher level of education to procure less risky jobs, thus are forced to engage in such occupations for ends means. This is further aggravated by their reckless driving and lack of implementation of road traffic safety measures coupled with the poor conditions of the road. This could be explained by the fact that it is easy to obtain drivers' licenses in the country, as well as the recklessness and speed used by some of these motorcyclists [14].

We noticed an alarming proportion of $20.5 \%$ of open fractures due to gunshots injuries. These were mostly individuals who were caught in the middle of the socio-political crisis of the country while either hiding in their farms or attempting to escape to the forest.

Majority of the fracture type were Gustilo-Anderson III. This is explained by the fact that most of the injuries were due to high energy mechanisms from road traffic crash and gunshots. Grade IIIA was the most common with 76 (39.0\%) cases, followed by grade IIIB with 56 (28.7\%) and grade II with 46 (23.6\%). Grade IIIC fractures were in minority with $17(8.7 \%)$ cases. These findings are similar to other studies that had predominantly grade III fractures [21] [22].

The majority of the fractures were comminuted 126 (64.6\%), transverse 28 (14.4\%), and oblique $26(13.3 \%)$. The left side (50.3\%) was found to be more af- 
fected than the right (49.2\%) side. Fractures of the tibia (38.5\%) were more common than those of the femur (16.4\%) and fibula (1.5\%) and this is because of its anteromedial and subcutaneous location compared to the compact muscular coverage of the femur. The distal segments $(41.0 \%)$ of these bones were commonly affected than the middle (38.5\%) and proximal segments (20.5\%). These findings are similar to studies carried out in Nigeria [17] [23].

The traditional golden 6 hours rule from time of injury to the first debridement has always been the basis of management of open fractures and the BOA/BAPRAS standards stress that debridement should be performed in a specialist center within 24 hours of injury [24]. Many controversies have occurred about the time of first debridement and the outcome of open fractures of long bones. This study showed that $46.7 \%$ of patients presented before 6 hours and $53.3 \%$ presented beyond 6 hours with the average time of 29.3 hours between injury and surgery. The reasons for the delayed presentation were mainly because they were either hiding from gunshots as a result of the socio-political crisis of the country or managed in another health facility or managed at home by traditional bone setters. However, patients who presented to the hospital more than 6 hours from injury with grade III fractures, had a statistically significant higher rate of wound infection, chronic bone infection, and non-union. This finding is similar to others studies in low-middle income setting [9] [25].

\section{Conclusion}

Open fractures of long bones of the lower limb involved mostly the young active male population. Road traffic crash accounted for a majority of the cases of open fractures. The tibia was the most fractured long bone and the most common fracture type and pattern were grade IIIA and comminuted fracture pattern respectively. The most common complications were wound infection, chronic osteomyelitis, limb shortening, mal-union, delayed union, and non-union.

\section{Limitations}

Some cases of open fractures of long bones in our context preferred to be treated by traditional bone setters; therefore, our data is smaller than the reality.

\section{Conflicts of Interest}

The authors declare no conflicts of interest regarding the publication of this paper.

\section{References}

[1] Odatuwa-Omagbemi, D.O. (2019) Open Fractures: Epidemiological Pattern, Initial Management, and Challenges in a Sub-Urban Teaching Hospital in Nigeria. Pan African Medical Journal, 33, Article No. 234. https://doi.org/10.11604/pamj.2019.33.234.18141

[2] Bennett, A.R. and Smith, K.D. (2013) (ii) Open Fractures. Journal of Orthopaedic Trauma, 27, 9-14. 
[3] Nogueira Giglio, P., Foga Cristante, A., Ricardo Pcora, J., Partezani Helito, C., Lei Munhoz Lima, A.L. and Dos Santos Silva, J. (2015) Advances in Treating Exposed Fractures. Revista Brasileira de Ortopedia, 50, 125-130. https://doi.org/10.1016/j.rbo.2014.05.011

[4] Ibeanusi, S.E.B. and Ekere, A.U. (2007) Epidemiology of Open Tibial Fractures in a Teaching Hospital. Port Harcourt Medical Journal, 1, 156-160. https://doi.org/10.4314/phmedj.v1i3.38876

[5] Twagirayezu, E., Dushimiyimana, J.M.V. and Bonane, A. (2008) Open Fractures I Rwanda: The Kigali Experience. East and Central African Journal of Surgery, 13, 77-84.

[6] Elniel, A.R. and Giannoudis, P.V. (2018) Open Fractures of the Lower Extremity: Current Management and Clinical Outcomes. EFORT Open Reviews, 3, 316-325. https://doi.org/10.1302/2058-5241.3.170072

[7] Nanchahal, J., Nayagam, S., Khan, U., Moran, C., Barrett, S., Sanderson, F. and Pallister, I. (2009) Standards for the Management of Open Fractures of the Lower Limb. Royal Society of Medicine Press, London.

[8] Di Schino, M., De Belenet, H., Drouin, C., Candoni, P., Gonzalez, J.F., Limouzin, J., et al. (2003) Réflexions sur la chirurgieorthopédiqueen milieu tropical. Revue $d u$ Rhumatisme, 70, 185-194. https://doi.org/10.1016/S1169-8330(02)00035-2

[9] Mathieua, L., Mottiera, F., Bertani, A., Danis, J., Rongiéras, F. and Chauvin, F. (2014) Management of Neglected Open Extremity Fractures in Low-Resource Settings: Experience of the French Army Medical Service in Chad. Orthopaedics \& Traumatology: Surgery \& Research, 100, 815-820.

https://doi.org/10.1016/j.otsr.2014.06.017

[10] Bickler, S.W., Weiser, T.G., Kassebaum, N., Higashi, H., Chang, D.C., Barendregt, J.J., et al. (2015) Global Burden of Surgical Conditions. In: Debas, H.T., Donkor, P., Gawande, A., Jamison, D.T., Kruk, M.E. and Mock, C.N., Eds., Disease Control Priorities. Essential Surgery, Vol. 1, 3rd Edition, International Bank for Reconstruction and Development/ World Bank, Washington DC, 19-40. https://doi.org/10.1596/978-1-4648-0346-8 ch2

[11] World Health Organization (2010) Injury and Violence: The Facts. World Health Organization, Geneva. https://apps.who.int/iris/bitstream/handle/10665/149798/9789241508018 eng.pdf

[12] Court-Brown, C.M., Bugler, K.E., Clement, N.D., Duckworth, A.D. and McQueen, M.M. (2012) The Epidemiology of Open Fractures in Adults. A 15-Year Review. Injury, 43, 891-897. https://doi.org/10.1016/j.injury.2011.12.007

[13] Larsen, P., Elsoe, R., Hansen, S.H., Graven-Nielsen, T., Laessoe, U. and Rasmussen, S. (2015) Incidence and Epidemiology of Tibial Shaft Fractures. Injury, 46, 746-750. https://doi.org/10.1016/j.injury.2014.12.027

[14] Chichom-Mefire, A., Palle-Ngunde, J., Fokam, P.G., Mokom-Awa, A., Njock, R. and Ngowe-Ngowe, M. (2018) Injury Patterns in Road Traffic Victims Comparing Road User Categories: Analysis of 811 Consecutive Cases in the Emergency Department of a Level I Institution in a Low-Income Country. International Journal of Surgery Open, 10, 30-36. https://doi.org/10.1016/j.ijso.2017.11.005

[15] Ngunde, P.J., Ngwa Akongnwi, A.C., Mefire, C.A., Puis, F., Gounou, E. and Nkfusai, N.C. (2019) Prevalence and Pattern of Lower Extremity Injuries Due to Road Traffic Crashes in Fako Division, Cameroon. Pan African Medical Journal, 32, Article No. 53. https://doi.org/10.11604/pamj.2019.32.53.17514

[16] Ariane, C., Drusia, D., Susana, N., Embolo, F.N., Chendjou, W., Wepngong, E., et 
al. (2020) Association of Health Care Use and Economic Outcomes after Injury in Cameroon. JAMA Network Open, 3, e205171.

https://doi.org/10.1001/jamanetworkopen.2020.5171

[17] Ikem, I., Oginni, L. and Bamgboye, E. (2001) Open Fractures of the Lower Limb in Nigeria. International Orthopaedics, 25, 386-388.

https://doi.org/10.1007/s002640100277

[18] Chua, W., Murphy, D., Siow, W., Kagda, F.H.Y. and Thambiah, J.S. (2012) Epidemiological Analysis of Outcomes in 323 Open Tibialdiaphyseal Fractures: A Nine-Year Experience. Singapore Medical Journal, 53, 385-389.

[19] Gopinathan, N.R., Santhanam, S.S., Saibaba, B. and Dhillon, M.S. (2017) Epidemiology of Lower Limb Musculoskeletal Trauma with Associated Vascular Injuries in a Tertiary Care Institute in India. Indian Journal of Orthopaedics, 51, 199-204.

[20] Kalande, F.M. (2018) Treatment Outcomes of Open Femoral Fractures at a County Hospital in Nakuru, Kenya. East African Orthopaedic Journal, 12, 52-55.

[21] Kombate, N.K., Walla, A., Akloa, K., Amakoutou, K., Bakriga, B., Ayouba, G., Dellanh, Y.Y., Abalo, A. and Dossim, A.M. (2017) Epidemiology of Open Limb Fractures in a Country with Low-Income. Open Journal of Orthopedics, 7, 356-361. https://doi.org/10.4236/ojo.2017.711036

[22] Frederico Carlos, J.N., Marina de Paula, C., Bernardo Aurelio, F.A., Pablício, M.F., Efferson, C.A. and Robson, A.S. (2016) Analysis of the Characteristics of Patients with Open Tibial Fractures of Gustilo and Anderson Type III. Revista Brasileira de Ortopedia (English Edition), 51, 143-149. https://doi.org/10.1016/j.rboe.2016.01.002

[23] Ikem, I., Oginni, L. and Ogunlusi, J. (2006) Determinants of Management Outcome in Open Tibia Fractures in Ile-Ife. Nigerian Journal of Surgical Research, 8, 81-83. https://doi.org/10.4314/njsr.v8i1.54845

[24] Ali, A.M., Noyes, D. and Cogswell, L.K. (2013) Management of Open Fractures of the Lower Limb. British Journal of Hospital Medicine, 74, 577-580. https://doi.org/10.12968/hmed.2013.74.10.577

[25] Bo, Y. and Vidmi Taolam, M. (2019) Etiology and Outcome of Open Fractures of the Extremities: A Single Center, Retrospective Study of 287 Patients. Journal of Bone Research, 6, Article No. 195. 